\title{
La rectitud es una cierta adecuación: la noción de verdad en Anselmo de Canterbury y Tomás de Aquino
}

\author{
Patricia Moya Cañas \\ UNIVERSIDAD DE LOS ANDES (CHILE) \\ pmoya@uandes.cl \\ Cristián Rodriguez Rodriguez \\ UNIVERSIDAD DE LOS ANDES (CHILE) \\ crodriguez@uandes.cl
}

\section{INTRODUCCIÓN}

Anselmo de Canterbury es, sin duda, la figura intelectual más relevante del siglo XI en el occidente latino y aunque ha pasado a la historia de la filosofía por el famoso argumento a favor de la existencia de Dios, llamado por Kant ontológico, hay mucho más que decir acerca de él en materia filosófica. Es el autor del primer tratado sistemático en la filosofía occidental que tiene por objeto exclusivo la cuestión de la verdad. El diálogo De Veritate (DV), escrito hacia el año 1085, repercute en el pensamiento de Tomás de Aquino, casi doscientos años después. En su Cuestión Disputada sobre la Verdad, escrita entre los años 1256-1259, el Aquinate dedica la primera cuestión al tema de la verdad y en ella se hace cargo de la definición anselmiana de la verdad como rectitud. Antes, en el Comentario a las Sentencias de Pedro Lombardo, había también comentado esta definición y posteriormente lo hará en la Suma Teológica al tratar este asunto.

Ambos autores conciben la verdad como una cierta relación de correspondencia entre dos miembros. En este trabajo nos proponemos comparar el modo en que cada uno de ellos entiende esta relación. Para poder comprender adecuadamente los aspectos comunes y divergentes, exponemos la noción de verdad de cada uno separadamente. La comparación destaca dos coincidencias y la divergencia entre la comprensión 
de la verdad como rectitudo y como adaequatio. A través del recorrido de la recepción de la definición anselmiana por Tomás de Aquino, se evidencian los rasgos peculiares de estos conceptos y la asimilación que hace el Aquinate de la rectitud a su definición de adecuación.

\section{La noción de verdad en el De Veritate de Anselmo de Canterbury}

El objetivo de esta parte del trabajo es esbozar la noción de verdad tal como Anselmo la presenta en su diálogo DV. Comienza esta obra con la formulación del problema: "Dado que creemos que Dios es la verdad y decimos que la verdad está en muchas otras cosas, quisiera saber si debemos reconocer que, cada vez que decimos que hay verdad, ella es Dios mismo" ". Tenemos dos premisas: una propia de la fe y otra proveniente de la experiencia cotidiana. Por la primera identificamos a Dios directamente con la verdad ${ }^{2}$. Por la segunda reconocemos que muchas cosas son verdaderas, son llamadas verdaderas o decimos que están en la verdad. Se quiere investigar de qué modo se puede explicar que haya muchas cosas verdaderas pero una sola verdad. El aspecto filosóficamente problemático de la verdad es su multiplicidad en relación a la unidad de un concepto o una palabra. Por lo mismo, su metodología apuntará a encontrar una definición de la verdad bajo la cual sea posible englobar los múltiples sujetos de los que ella puede ser predicada ${ }^{3}$. Esto implicará examinar estos sujetos y hallar preliminarmente un concepto formal que conecte estos casos y luego especificar la definición. Si bien en el DV Anselmo no explica con claridad qué se persigue al buscar una definición, en su diálogo De Libero Arbitrio aclara que la búsqueda de

Anselmo de Canterbury, De veritate [DV] I, 176: Quoniam deum veritatem esse credimus, et veritatem in multis aliis dicimus esse, vellem scire an ubicumque veritas dicitur; deum eam esse fateri debeamus. (Citaremos siguiendo la edición de las Obras Completas de S. Anselmo: S. Anselmi Cantuarensis Archiepiscopi Opera Omnia. F. S. Schmitт (ed.), (Friedrich-Fromann Verlag, Stuttgart-Bad Canstatt, 1968), indicando en números romanos el capítulo correspondiente y luego la página de acuerdo a esta edición).

2 Nótese que esta identificación es asumida por Anselmo expresamente desde la fe, sin intentar hasta este punto, hacer una demostración racional de ella. En Monologion XVIII (Opera Omnia I, 33), Anselmo solo llega a mostrar que es necesario que exista una verdad eterna siguiendo un argumento semejante al de Agustín en los Soliloquios (cf. I, 15, 28-29 y II, 2, 2).

3 DV I, 176-177: [S] i vis quaeramus per rerum diversitates in quibus veritates dicimus esse, quid sit veritas. 
una definición requiere de un concepto que sea el mismo para todos los ejemplares definiendum, y "no contenga ni más ni menos"4. Esta misma metodología opera en el DV, puesto que un concepto formal tiene que ser responsable de darle unidad a las distintas acepciones de verdad que se irán examinando. Para esto, Anselmo utiliza una metodología tópica, esto es, una investigación pretendidamente exhaustiva de los "lugares de la verdad" (sedes veritatis ${ }^{5}$ ), es decir, de todos y cada uno de los distintos tipos de X en los que se puede decir "X es verdadero". Esta suerte de inducción permitirá comprender qué es lo que queremos decir cuando decimos que algo es verdadero y qué relación guarda esto con Dios, entendido como la summa veritas.

En el diálogo se encuentra esta enumeración de todos los lugares de la verdad: la proposición verdadera (cap. II), la opinión o pensamiento verdadero (cap. III), la voluntad (cap. IV) y la acción verdadera (cap.V y IX), la verdad de los sentidos (cap.VI), la verdad de las esencias de las cosas (cap.VII) y la summa veritas (cap.VIII y XIII). En estos capítulos se buscará articular las verdades particulares con la suma verdad. Como se puede apreciar en esta lista, las sedes veritatis incluyen categorías que usualmente no se consideran como sujetos de verdad, por ejemplo, la verdad de la voluntad y de la acción ${ }^{6}$. Como esperamos mostrar, la estructura anselmiana de la verdad permitirá entender también la predicación de verdad en el ámbito práctico a través del concepto de rectitudo. Con este objetivo analizaremos la rectitud en dos de las formas principales de la verdad: la proposicional y la práctica. Luego examinaremos la definición de verdad como rectitud para terminar explicando cómo toda verdad se subordinaría a la summa veritas.

4 Anselmo de Canterbury, De Libero Arbitrio I, 208: Licet enim animal differat ab animale siue substantialiter siue accidentaliter, definitio tamen secundum nomen animalis omnibus animalibus est eadem. Quapropter talem oportet dare definitionem libertatis arbitrii, quae nec plus nec minus illa contineat.

5 DV VI, 183: Putasne nos praeter summam veritatem omnes sedes invenisse veritatis?, M. Enders en Über die Wahrheit. Übersetzung, Einleitung und Anmerkungen, (FelixMeinerVerlag, Hamburg, 2001), xviii-xxvii desarrolla las características de este método tópico y sus antecedentes latinos en Cicerón.

6 Ya en Ética a Nicómaco VI, 2 Aristóteles había desarrollado su doctrina sobre la verdad práctica. Sin embargo, no parece haber evidencia de que el Cantuarense haya tenido contacto con textos de Aristóteles fuera del Organon, cf. J. Marenbon, "Anselm and the Early Medieval Aristotle», en J. Marenbon (ed.) Aristotle in Britain during the Middle Ages (Turnhout, Brepols, 1996), 1-19. 


\subsection{La rectitudo y la verdad proposicional}

La verdad proposicional (veritas enuntiationis), posee una primacía respecto de los demás sentidos de verdad, ya que, según Anselmo, es el caso más frecuente (saepius) del reconocimiento de la verdad ${ }^{7}$. Allí es donde se da paradigmáticamente la estructura fundamental de la verdad, razón por la cual sería el modelo inicial del DV.

La enunciación es verdadera cuando lo que ella enuncia $e s^{8}$, y en este caso, significa lo que debe significar". Esta es la enunciación que "hace lo que debe", la que cumple su fin y, por tanto, es la enunciación recta ${ }^{10}$. Así, deducen los dialogantes, la proposición es verdadera cuando enuncia lo que debe enunciar, o dicho de otro modo, cuando enuncia correctamente o con rectitud. De esta manera se obtiene provisionalmente un concepto formal para comprender las múltiples verdades: la rectitudo ${ }^{11}$.

DV II, 177: Quaeramus ergo primum quid sit veritas in enuntiatione, quoniam hanc saepius dicimus veram vel falsam.

8 DV loc. cit:: Quando est quod enuntiat, sive affirmando sive negando. Esta fórmula remitiría a la descripción aristotélica de la verdad en Metafísica IV, 4, aunque no tenemos certeza si es que Anselmo tuvo acceso a este texto, cf. J. Marenbon, «Anselm and the Early Medieval Aristotle». Lo que sí podemos afirmar que la inspiración original de la investigación anselmiana por la verdad se encuentra en Agustín, específicamente en Soliloquii y en De Doctrina Christiana, como se ve en J. Hopkins, «Anselm of Canterbury», en J. Gracia-T. Noone (eds.), A Companion to Philosophy in the Middle Ages, (Blackwell, Oxford, 2002), 138-151. A. D'Ors examina esta dependencia agustiniana en "Non erat veritas", "non erit veritas". Sobre las pruebas anselmianas de la eternidad de la verdad", en S. Castellote (ed.). Verdad, Percepción, Inmortalidad. Miscelánea en homenaje al Profesor Wolfgang Strobl (Facultad de Teología San Vicente Ferrer, Valencia, 1995), 203-205.

9 Los términos enuntiatio y significatio en este autor no son en absoluto idénticos. La enuntiatio es la proposición, mientras que la significatio es la relación entre la enuntiatio y las cosas mentadas por ella. Cf. J. Marenbon, "Anselm and the Early Medieval Aristotle», 1-19; cf. ENDERs, Über die Wahrheit. Übersetzung, Einleitung und Anmerkungen, 81-83.

10 DV II, 178: Magister [M]:Ad quid facta est affirmatio? Discipulus [D]: Ad significandum esse quod est. $M$ : Hoc ergo debet. D: Certumest. M: Cum ergo significat esse quod est, significat quod debet.

11 DV II, 179: M: Ergo non est illi [sc. significationi] aliud veritas quam rectitudo. D: Aperte nunc video veritatem hanc esse rectitudinem. La introducción del concepto de rectitud no es una innovación de Anselmo, sino se encuentra presente a lo largo de la tradición cristiana, como también platónica y estoica. Cf. M. DreYer, «Veri- 
Como se verá, este "hacer lo que se debe" se identifica, entonces, con la rectitud $^{12}$.

Este concepto formal de rectitud es la estructura fundamental con la que Anselmo articulará los distintos sentidos de verdad investigados. La vía para determinar en qué consiste la verdad de la opinión o del pensamiento, será semejante a la de la verdad proposicional: "se nos dio el poder de pensar que algo sea o no sea, para que pensemos si es que es o no. Por tanto, quien piensa que lo que es, es, piensa lo que debe y así el pensamiento es recto [...]. La verdad [del pensamiento] no es otra cosa que la rectitud"13. En este texto se pone de relieve un aspecto particular de su idea de rectitud: el que se cumpla el deber. Es decir, el fin para el cual se nos otorgó una facultad como es la de pensar (nobis datum est). Más adelante, Anselmo reconduce la verdad de los sentidos (sensuum veritas) a la verdad del pensamiento, pues la rectitud se da cuando se piensa algo sobre los datos obtenidos a través de los sentidos ${ }^{14}$.

Si entendemos en la verdad proposicional la rectitud como hacer lo que debe, esto es, cumplir con su función propia que es significar, cabe preguntarse: ¡es entonces verdadera una proposición que significa, pero lo hace de forma errónea (i.e. indica que es aquello que, en realidad, no es)? El maestro reconoce que la objeción tiene sentido e indica que el carácter intencional de la proposición genera una suerte de "doble rectitud" 15 , puesto que la proposición que significa de manera errónea,

tas-Rectitudo-Iustitia. Grundbegriffe ethischer Reflexion bei Anselm von Canterbury», en Recherches de Théologie et PhilosophieMédiévales, 1/64 (1997), 77, 67-85.

12 DV loc. cit.: M:[V]eritatem et rectitudinem habet, quia facit quod debet.

13 DV III, 180: M:[N]amque nobis datum est posse cogitare esse uel non esse aliquid, ut cogitemus esse quod est, et non esse quod non est. Quapropter qui putat esse quod est, putat quod debet, atque ideo recta est cogitatio (...) non est aliud eius ueritas quam rectitudo. Al respecto afirma D’Ors: “"La verdad del pensamiento, en opinión de San Anselmo, no radica primariamente en la mera conformidad del pensar con la "res cogitata", sino en la conformidad del pensar con su propio fin, de la que resulta esta otra conformidad"". "Non erat veritas", "non erit veritas". Sobre las pruebas anselmianas de la eternidad de la verdad, 210.

14 DV VI, 183: M: Non mihi uidetur haec ueritas uel falsitas in sensibus esse sed in opinione. Ipse namque sensus interior se fallit, non illi mentitur exterior.

15 Cfr. T. Williams \& S. Visser, “Anselm's Account of Freedom”, en Canadian Journal of Philosophy, 2/31(2001), 221-244. Estos autores identifican un doble sentido de la rectitud de la proposición a partir de la distinción entre tipo (type) e individuo (token), en el sentido de que una proposición es siempre verdadera en 
en un sentido, está haciendo lo que debe -significar- aunque lo esté haciendo de manera falsa.

"Cuando <la enunciación> significa que es lo que es, hace lo que debe en un doble sentido: puesto que indica tanto lo que recibe <como tarea> el significar, como también aquello para lo que está hecha. Sin embargo, según esta rectitud y verdad por la que se significa que es lo que es, la enunciación es llamada por su uso verdadera y correcta; y no por aquella rectitud por la que indica también que es lo que no es. En efecto, más debe a causa de que recibe <la tarea de> la significación de que no la reciba. Pues, no recibe $<$ como tarea $>$ indicar que es una cosa que no es, o que no es cuando sí es, salvo que no pueda dársele el indicar que es cuando es, o el que no sea cuando no es" ${ }^{16}$.

En este pasaje, Anselmo afirma que el solo establecer una relación de referencia respecto de un cierto estado de cosas ya es, en cierto modo, una significatio, sin perjuicio del cumplimiento fáctico de su verdad. En ese sentido, también una proposición falsa "hace lo que debe". Sin embargo, esta clase de rectitud solo tiene sentido en función de la rectitud plena, de la cual es derivada. Pero resulta importante, como indica el mismo Anselmo al final del párrafo, en el caso que no puede atribuírsele con claridad su verdad o falsedad. En otros términos, una proposición cuya verdad ignoramos, es significativa y en este sentido amplio, recta y verdadera, aun al no cumplirse formalmente la indicación de que es lo que de hecho sea.

El cumplimiento pleno de la verdad se da cuando significa con rectitud por el uso (usu), es decir, cuando indica que es lo que de hecho sucede. El doble sentido de la rectitud ofrece dos aspectos diferentes: el primero, la significación. Esta es inmutable, se da siempre y es natural. El segundo aspecto, la significación verdadera, es más pleno, es muta-

su tipo, pero su ejemplar individual o token será verdadero o falso conforme a las circunstancias y al uso de esa proposición.

16 DV II, 179: M:[C]um significat esse quod est, dupliciter facit quod debet; quoniam significat et quod accepit significare, et ad quod facta est. Sed secundum hanc rectitudinem et ueritatem qua significat esse quod est, usu recta et uera dicitur enuntiatio; non secundum illam qua significat esse etiam quod non est. Plus enim debet propter quod accepit significationem, quam propter quod non accepit. Non enim accepit significare esse rem cum non est, uel non esse cum est, nisi quia non potuit illi dari tunc solum modo significare esse quando est, uel non esse quando non est. 
ble, no se da siempre y es accidental, puesto que depende del uso ${ }^{17}$. Un mismo enunciado es siempre recto y verdadero en el primer sentido, pero solo será recto y verdadero en el segundo sentido, en la medida que se adecúe a un cierto estado de cosas en el mundo. El Cantuarense nota también que hay proposiciones analíticas en las que siempre se dan las dos rectitudes simultáneas, tales como "el hombre es animal" o "el hombre no es piedra" 18 , es decir, son proposiciones siempre verdaderas en virtud de sus elementos.

\subsection{Rectitudo como verdad práctica}

De la lista de sedes veritatis presentada más arriba destacan dos clases vinculadas al ámbito práctico, a saber, la verdad de la voluntad y la verdad de la acción. El fundamento para incluir estas categorías es una exigencia bíblica, pues encontramos pasajes del Evangelio en los que se afirma que el demonio "no permaneció en la verdad", o quien "obra en la verdad, viene a la luz"19. Como hemos visto hasta ahora, entender la verdad como rectitud y, esta a su vez, como cumplimiento, o un hacer lo que se debe, permite entonces aplicar sin dificultad la misma estructura en el ámbito práctico. La verdad de la voluntad consistirá en querer lo que se debe querer ${ }^{20}$, mientras que la verdad de la acción será, por consiguiente, obrar bien o con rectitud, y así en la forma que se debe $\mathrm{obrar}^{21}$.

17 DV loc. cit:: M: Alia igitur est rectitudo et ueritas enuntiationis, quia significat ad quod significandum facta est; alia uero, quia significat quod accepit significare. Quippe ista immutabilis est ipsi orationi, illa uero mutabilis. Hanc namque semper habet, illam uero non semper. Istam enim naturaliter habet, illam uero accidentaliter et secundum usum. Véase también D’Ors, “"Non erat veritas»”, “"non erit veritas»". Sobre las pruebas anselmianas de la eternidad de la verdad», 206-208.

DV loc. cit.: M: Quamuis in quibusdam enuntiationibus inseparabiles sint istae duae rectitudines seuueritates; ut cum dicimus: homo animal est, aut: homo lapis non est.

19 Cf. Jn 8, 44 y 3, 21, respectivamente. Cf. G.R. Evans, Getting it Wrong. The Medieval Epistemology of Error (Brill, Leiden, 1998), 201. Recordemos que el fin de este diálogo filosófico es intentar esclarecer un problema de motivación teológica y exegética.

20 DV IV, 181: M: Nam si quamdiu uoluit quod debuit, ad quod scilicet uoluntatem acceperat, in rectitudine et in ueritate fuit, et cum uoluit quod non debuit, rectitudinem et ueritatem deseruit: non aliud ibi potest intelligi ueritas quam rectitudo, quoniam siue ueritas siue rectitudo non aliud in eius uoluntate fuit quam uelle quod debuit.

21 DV V, 181: M: [S]ententia est omnium quia qui facit quod debet, bene facit et rectitudinem facit. Unde sequitur quia rectitudinem facere est facere ueritatem. 
Tal como se aprecia en todos estos casos, se puede ver que Anselmo entiende la rectitudo como un cierto cumplimiento de la finalidad propia de cada uno de estos sujetos, indicado por la expresión "hacer lo que debe". Por lo tanto, que un sujeto $\mathrm{X}$ sea verdadero dependerá de que $\mathrm{X}$ realice efectivamente aquella función que se le fue $\mathrm{dada}^{22}$.

\subsection{La definición de la verdad: rectitudo sola mente perceptibilis}

En el capítulo XI, una vez testado el modelo de la rectitud en todos los lugares de la verdad, Anselmo matiza: también se habla de la rectitud que tienen las cosas sensibles, como por ejemplo, la de una vara o una cierta superficie plana. No obstante, esta rectitud geométrica no parece indicar ninguna correspondencia en el sentido que lo hemos desarrollado hasta aquí. La diferencia entre esta rectitud visible y la rectitud de la verdad dice relación con su modo de acceso epistemológico. La rectitud visible puede ser reconocida por lo sentidos, como también por la razón (por ejemplo, mediante una demostración geométrica sin que exista necesariamente una línea visible). En cambio, la rectitud propia de la verdad no puede ser reconocida por los sentidos, sino que solo puede ser percibida por la razón. De este modo se termina de formular la definición de verdad: rectitudo mente sola perceptibilis, una rectitud que solo puede ser percibida por la mente ${ }^{23}$.

Sin embargo, esta idea de rectitudo no indica sin más una suerte de correspondencia estructural entre un cierto truthbearer (i.e. proposición) y un truthmaker (i.e. estado de cosas), tal como lo plantea la teo-

22 Según la hipótesis de SöHngen, tal noción de rectitudo tendría su origen en el concepto teológico-jurídico de la satisfactio que Anselmo desarrolla en Cur Deus Homo I 19-20 (II, 84-88), cf. G. SöHngen, "Rectitudo bei Anselm von Canterbury als Oberbegriff von Wahrheit und Gerechtigkeit” en H. Kohlenberger (ed.), Sola Ratione. Anselm Studien für Pater F. S. Schmitt OSB zum 75. Geburtstag (Friedrich Frommann Verlag, Stuttgar-Bad Canstatt, 1970), 71-77. Cf. también M. DreYER, «Veritas-Rectitudo-Iustitia. Grundbegriffe ethischer Reflexion bei Anselm von Canterbury», 80-81.

23 DV XI, 191: M: Dic ergo mihian tibi videatur esse aliqua rectitudo praeter has quas contemplati sumus. D: Non alia praeter has nisi illa quae est in rebus corporeis, quae multum est aliena ab istis, ut rectitudo virgae. $M$ : In quo illa tibi videtur differre ab istis? D: Quia illa visu corporeo cognosci potest, istas rationis capit contemplatio. (...) [E]adem quae sic ratione intelligetur, visu sentitur in subiecto. Illae vero non nisi sola mente percipi possunt. M: Possumus igitur; nisi fallor, definiré quia veritas est rectitudo mente sola perceptibilis. 
ría contemporánea de la correspondencia ${ }^{24}$. La rectitud planteada por Anselmo no es de orden meramente descriptivo, es decir, la semejanza estructural entre un enunciado y aquello que se enuncia, sino más bien de orden teleológico: el sujeto de verdad es en efecto verdadero cuando realiza aquello para lo cual fue hecho, esto es, cumple su propio $f \mathrm{in}^{25}$. La rectitud anselmiana no designa primariamente una conformación de tipo proposición-mundo, sino más bien proposición-función de la proposición (i.e. significar). Así, por ejemplo, la proposición es verdadera cuando cumple su fin, que es enunciar correctamente; la acción es verdadera cuando cumple su fin, que es hacer lo que se debe, y así sucesivamente. En cierto modo, esta noción de verdad exige la realización de una función propia por parte del truthbearer, definida por aquello que debe hacer. Solo entonces, y en algunos casos, encontramos que la realización propia involucra una cierta correspondencia en el sentido usual del término. En el caso de la proposición, por su carácter referencial (significatio), la rectitud existirá plenamente cuando ella realice su cometido propio, es decir cuando su descripción del contenido sea correcto en relación a su objeto ${ }^{26}$. La noción anselmiana de verdad involucra necesariamente la razón de fin, y solo por el cumplimiento de tal fin podemos predicar correctamente el que algo sea verdadero.

Por lo demás, cabe notar que la rectitud es perceptible por la mente sin que esta conformidad sea lo constitutivo la verdad -como sí sucederá en Tomás de Aquino- sino más bien esta preexiste al conocimiento que

24 La terminología de truthbearer (portador de la verdad) y truthmaker (lo que hace verdad) se ha estandarizado en las discusiones contemporáneas en teoría de la correspondencia. Cf. M. DAvid, «The Correspondence Theory of Truth», en Stanford Encyclopedia of Philosophy. En http://plato.stanford.edu/entries/truth-correspondence/ revisado el 24 de julio de 2013.

25 Williams \& Visser, “Anselm's Account of Freedom”, 223: "Rectitude (correctness) is a fundamentally teleological notion: statements are correct when they do what they were designed to do".

26 E. J. Ashworth, "Language and Logic" en A.S. McGrade (ed.), The Cambridge Companion to Medieval Philosophy, (Cambridge University Press, Cambridge 2003), 92. Este autor interpreta la correspondencia como una relación entre la proposición, las cosas y las ideas divinas. En los textos referentes al problema de la verdad no encontramos referencia a una doctrina de las Ideas en relación a la rectitudo, lo que no quita que en último término el referente sea la summa veritas, es decir, Dios mismo. 
tengamos de ella. La verdad es la rectitud entre un truthbearer y su función, y no la captación intelectual que tengamos de aquella rectitud ${ }^{27}$.

El concepto de rectitud involucra otro elemento: en cada una de las sedes veritatis hay una cierta tarea que se recibe (accepit) y en este aspecto cobra sentido el deber de cada cual. Esto ya lo indicamos antes, cuando se pregunta para qué "se nos dio" el pensar. Del hecho de que los distintos sujetos de la verdad tengan un origen en algo o alguien distinto, se sigue, piensa Anselmo, que han de cumplir una función determinada conforme a su origen ontológico: "Si el fuego recibe el calentar desde aquel de quien tiene el ser, al calentar, hace lo que debe" ${ }^{28}$. La función propia de cada cosa, de la que depende su rectitud y su verdad, depende en último término de haberla recibido, y en este sentido, remite a su creador ${ }^{29}$.

Tal como se advierte en la lectura del DV, el concepto de rectitudo no designa únicamente una semejanza estructural, sino que tiene una connotación teleológica y, por ende, normativa. Bajo la razón de rectitud no entendemos únicamente que dos relata se conformen entre sí, sino que tal conformidad responde a un deber-hacer específico ${ }^{30}$. De esta forma, Anselmo no tiene dificultades en ampliar el concepto de verdad hacia ámbitos no proposicionales de orden práctico, como la voluntad o la acción. Ambas categorías pueden perfectamente comprenderse desde la rectitud.

\subsection{Subordinación de toda verdad a la summa veritas}

El modelo de la verdad como rectitudo permite comprender qué significa que todos los sujetos de verdad, ya sean del ámbito sensible, intelectual o práctico, puedan recibir ese predicado. Ahora el autor se enfrenta al pro-

27 DV XIII, 197: [N] on existente significatione non perit rectitudo qua rectum est et qua exigitur, ut quod significandum est significetur.

28 DV V, 182: Si ignis ab eo a quo habet esse accepit calefacere: cum calefacit, facit quod debet.

29 Cf. A. Hubert, «El enigma del hombre según Anselmo de Canterbury», en Teología y Vida, 45 (2004), 509-510. Este autor incorpora la idea de rectitud como recepción al modo de clave antropológica para comprender la estructura del ser humano según Anselmo. Su noción central es la correspondencia entre Dios y el hombre, a través de la rectitud: "la verdad es algo que hay que recibir. Además, la rectitud es el actuar correcto. Aquí es el actuar correcto para recibir”, 510.

30 En este punto hay consenso en los intérpretes. Cf. D.S. Theron, «Morality as Right Reason", en The Monist, 1/66 (1983), 26-38; Evans, Getting it Wrong. The Medieval Epistemology of Error, 56. 
blema fundamental de este tratado: ¿qué relación hay entre la verdad creada y Dios, la summa veritas? Porque si detenemos el diálogo aquí, tendríamos que asumir que Dios es, en efecto, el fundamento de la verdad porque es el origen de donde proceden las diversas funciones que cada cosa debe cumplir para ser verdadera. Sin embargo, ¿̇es Dios verdadero en este mismo sentido teleológico? "No negarás que la suma verdad es una rectitud", afirma el maestro ${ }^{31}$. ¿Tendría que ser Dios, entendido como suma verdad, una rectitud respecto de otra cosa y cumplir un fin? Más bien al revés: la summa veritas no debe corresponderse o adecuarse a nada, sino que todos se deben a ella en cuanto causa, y por tanto, en cuanto finalidad. La verdad de las cosas es efecto de la summa veritas, y toda otra verdad, en último término, es causada por las cosas. Como afirma el discípulo:

"Al ser la verdad que está en la existencia de las cosas es efecto de la suma verdad, la misma también es causa de la verdad que está en el pensamiento, y a su vez ella de la que está en la proposición. Estas dos verdades, por su parte, no son causa de ninguna verdad" 32 .

Podemos trazar una doble relación de causalidad entre la suma verdad y la verdad de las cosas, y la verdad de las cosas, y las demás sedes veritatis. En definitiva, toda rectitud remite a Dios como causa de toda rectitud. Pero ¿̇es en sí mismo una rectitud? Si es summa veritas, tiene que serlo. Entonces, cabe aplicar una distinción de los comentaristas entre dos sentidos del término rectitudo en Anselmo: 1) rectitud como concepto relacional, y 2) rectitud como concepto de identidad ${ }^{33}$. En el caso de la summa veritas tendríamos que explicar que hay una identidad completa entre el portador de verdad y lo que este portador de verdad debería llevar a cabo, lo cual está determinado por su finalidad, como dijimos antes. En el caso de Dios, entonces, se identifica lo que es y lo que debe ser, puesto que su misma esencia es la que determina lo que las cosas deben $\operatorname{ser}^{34}$. Esta identidad es, no obstante, una rectitud consigo mismo,

31 DV X, 189: Summam autem ueritatem non negabis rectitudinem esse.

32 DV X, 190: Ut cum ueritas qua est in rerum existentia sit effectum summae ueritatis, ipsa quoque causa est ueritatis quae cogitationis est, et eius quaeest in propositione; et istae duae ueritates nullius sunt causa ueritatis.

33 Cf. Enders, Über die Wahrheit. Übersetzung, Einleitung und Anmerkungen, LXVI LXX. Véase también, E. Recktenwald, Die ethische Struktur des Denkens von Anselm von Canterbury (Carl Winter Verlag, Heidelberg, 1998).

34 Esta idea anselmiana de una rectitud idéntica a sí misma y, por tanto, fuente de toda rectitud tuvo una fuerte repercusión en el pensamiento teológico de Karl Barth, 
lo que garantiza que el concepto formal de rectitud permite comprender también bajo sí la verdad divina. Dios es la rectitud misma, lo recto en sí mismo y, por tanto, causa y fuente de todo aquello que pueda recibir también la rectitud. El que algo particular y finito sea verdadero, quiere decir que se rectifica por cumplir su fin específico, plegándose así a la rectitud absoluta e idéntica en sí misma.

Sin querer profundizar en el contexto metafísico del pensamiento anselmiano sobre la verdad, al entender a Dios como la rectitud en sí misma y cada verdad particular como la realización del facere quod debet, esto es, del cumplimiento de su fin específico, Anselmo entiende que toda verdad es una cierta participación de la rectitud divina. El hecho de que algo sea verdadero -i.e. una proposición o una acción-son imitaciones finitas de la rectitud, cualidad propiamente divina. Esto hace que la verdad no sea entendida solo como la conmesuración a las ideas divinas o a la voluntad de Dios, sino como la actualidad de una perfección. Esta participación formal es lo que le permite a Anselmo resolver el problema inicial del diálogo: ¿cómo entender la multiplicidad de verdades finitas y reconocer a Dios mismo como la verdad? "La suma verdad, subsistente por sí misma, no es <verdad $>$ de ninguna cosa en particular, pero cuando algo existe en conformidad con ella, entonces se llama verdad o rectitud" 35 .

\section{La NOCión DE VERDAd en TOMÁs de Aquino}

Tomás de Aquino trata la noción de verdad en diferentes momentos de su obra buscando una definición que exprese adecuadamente este concepto. Para esto, compara y relaciona sus resultados con otras definiciones entre las que se encuentran aquellas de Anselmo particularmente en su diálogo De veritate. En dos de sus obras tempranas, el Comentario a las Sentencias ${ }^{36}$ y la Cuestión Disputada sobre la Verdad (De Veritate), comprende la verdad como la adecuación entre el entendimiento y la cosa. La fórmula aparece más claramente en el De veritate y se repite

como plantea R. Hartman, «Prolegomena to a Meta-Anselmian Axiomatic», en Review of Metaphysics 4/14(1961) 637-675.

35 DV XIII, 199: [S] umma ueritas per se subsistens nullius rei est; sed cum aliquid secundum illam est, tunc eius dicitur ueritas uel rectitudo.

36 Cf. Tomás de Aquino, Scriptum Super Sententiis Liber I [In I Sent.] d. 19, q. 5, a. 1. (Los textos de Tomás de Aquino han sido extraídos de la versión digital del Corpus Thomisticum, http://www.corpusthomisticum.org/iopera.html). 
más tarde en la cuestión 16 de la primera parte de la Suma Teológica ${ }^{37}$. Expondremos sintéticamente la doctrina tomasiana de la verdad que se expresa en esta definición que se ha vuelto clásica. Como es sabido, Tomás dedica la primera cuestión del De veritate al tema de la verdad, las demás cuestiones versan sobre otros temas, muchos de ellos relacionados con el conocimiento. Nos centraremos en este texto que resume y expresa su pensamiento constante en el tiempo.

\subsection{La verdad y el ente}

La primera pregunta que Tomás formula es si lo verdadero añade o no algo a la noción de ente. Esta cuestión dará lugar a la enumeración de los llamados trascendentales del ser, entre los cuales la verdad o lo verdadero expresa la conveniencia del ente con el entendimiento, es decir, añade a la noción de ente esta relación ${ }^{38}$. Desde el comienzo del De veritate se afirma que la sede de la verdad o de lo verdadero está en la conveniencia del ente con el entendimiento: "Todo conocimiento se cumple por la asimilación del cognoscente a la cosa conocida, de tal suerte que a esta asimilación se le llama causa del conocimiento, así como la vista conoce el color por el hecho de ser informada por la especie del color" ${ }^{39}$. En este mismo texto se define, por primera vez, la verdad como adecuación de la cosa y el entendimiento. Antes de centrarnos en esta definición, conviene destacar que para Tomás de Aquino el ente y lo verdadero están estrechamente ligados. Sirviéndose de definiciones de la verdad utilizadas por autores anteriores, afirma que es verdadero "aquello que es" o que "es verdadero aquello que manifiesta y declara el ser" ${ }^{20}$. En la cuestión paralela de la Suma Teológica formula de una manera más taxativa esta idea: "el ser del objeto, no su verdad, causa la verdad del entendimiento" ${ }^{41}$.

37 Cf. Tomás de Aquino, Summa Theologiae [STh.] I, 16, 2.

38 Tomás de Aquino, Quaestio Disputata De Veritate [De veritate] I, 1: Hoc est ergo quod addit verum super ens, scilicet conformitatem sive adaequationem rei et intellectus.

39 De veritate I, 1: Omnis autem cognitio perficitur per assimilationem cognoscentis ad rem cognitam ita quod assimilatio dicta est causa cognitionis, sicut visus per hoc quod si ponitur secundum speciem coloris cognoscit colorem.

40 De veritate I, 1: "Verum est id quod est»; "sic dicit Hilarius quod "Verum est declarativum et manifestativum esse». F. CANALs en Sobre la esencia del conocimiento, (PPU, Barcelona, 1987), 553-555 enfatiza el hecho de que el ser, la actualidad del ente, es el fundamento del ser conocido.

${ }^{41}$ STh, I, 16, 1 ad 3: Et similiter ese rei, non veritas eius, causat veritatem intellectus. 


\subsection{La verdad como adaequatio}

Pero la noción de verdad, su ratio, se realiza formalmente en la adecuación, porque ella da cuenta de la relación de correspondencia o conveniencia entre el entendimiento y la cosa. La preminencia de la adecuación como definición de la verdad tiene como consecuencia importante que la verdad siempre se entiende por su relación con algún entendimiento, ya sea el divino o el humano ${ }^{42}$. La verdad del ente y la verdad de la proposición o del entendimiento caen bajo esta relación porque, por una parte, el ente es verdadero por su dependencia al entendimiento divino que lo crea; la proposición, por otra parte, es verdadera porque el entendimiento humano se ajusta a aquello que la cosa es. De la misma manera se realiza la verdad del intelecto práctico: en este caso la cosa fabricada o la acción se realizan en conformidad con la mente del que las ha pensado y que es su autor.

Desde esta perspectiva, el ser veritativo no pertenece de suyo a la cosa, aunque esta lo fundamente, sino que es una propiedad del hecho de que la cosa es conocida. Por esta razón, Tomás afirma que si no hubiese ningún entendimiento, no habría propiamente algo verdadero o no se realizaría esta forma de ser, porque no existiría la medida conforme a la cual se cumple o no se cumple la adecuación veritativa:

"[...] por esto es que aun cuando el entendimiento humano no existiera, incluso así, las cosas se dirían «verdaderas» en relación al entendimiento divino. Pero si supusiésemos suprimidos ambos entendimientos -lo que es imposible- de ningún modo permanecería la noción de verdad" ${ }^{43}$.

42 Cf. Jan A. Aertsen, La filosofía medieval y los trascendentales (Eunsa, Pamplona, 2003), 242: "La idea básica que atraviesa la exposición de Tomás, es que la relación con el intelecto es esencial para la verdad. En los tres escritos en los que presenta un estudio sistemático de la verdad, cita un texto del libro VI de la Metafísica de Aristóteles (c. 4, 1027b 25) a propósito de que «la verdad y la falsedad no existen, como el bien y el mal, en las cosas, sino en la mente». El lugar propio de la verdad está en el intelecto. Esta tesis constituye un gran obstáculo para cualquier concepción puramente ontológica de la verdad".

43 De veritate, I, 2: unde etiam si intellectus humanus non esset, adhuc res verae dicerentur in ordine ad intellectum divinum; sed si uterque intellectus, rebus remanentibus per impossibile, intellegeretur auferri, nullo modo ratio veritatis re maneret. A. LLANO hace ver la dependencia del ser veritativo, propio de la verdad lógica, del ser verdadero ontológicamente considerado. Pero también esta distinción permite compren- 
La noción de verdad como correspondencia se puede asimilar a la doctrina tomasiana en la medida en que esta se interprete al modo aristotélico. Así dice en el De veritate: "La verdad, que es causada en el alma por las cosas, no sigue la estimación del alma sino la existencia de las cosas. Y, en efecto, de una oración se dice que es verdadera o falsa, y lo mismo del entendimiento, por el hecho de que la cosa es o no es" ${ }^{44}$. Este texto es semejante al de la Metafísica en el que Aristóteles dice: "se ajusta a la verdad el que piensa que lo separado está separado y que lo junto está junto, y yerra aquel cuyo pensamiento está en contradicción con las cosas" ${ }^{\prime 5}$.

Con respecto al entendimiento divino, surge la pregunta de si se da o no en Él una adecuación, pues al ser el origen de toda verdad tendría que adecuarse solo consigo mismo. Trataremos ese punto al ver el carácter analógico de la verdad y su realización en Dios.

\subsection{LA VERDAD LÓGICA Y ONTOLÓGICA}

Ya Aristóteles en la Metafísica plantea dos formas de entender la verdad: una ontológica y otra lógica. La verdad que le pertenece a la cosa por el hecho de ser y la verdad como propiedad del entendimiento respectivamente $^{46}$. Como ya se ha dicho, para Tomás de Aquino la verdad es un

der mejor el caso de las negaciones o privaciones que se dicen con verdad, pero que no se corresponden con un ser real. Ver «"Being as True" according to Aquinas», en Acta Philosophica, $1 / 4$ (1995) 73-82.

44 De veritate, I, 2, ad 3: similiter et veritas, quae est in anima causata a rebus, non sequitur aestimationem animae sed existentiam rerum "quoniam eo quod res est vel non est, dicitur oratio vera vel falsa", similiter et intellectus.

45 Aristóteles, Metafísica, IX, 10, 1051b 3-9. Tanto la doctrina aristotélica de la verdad como correspondencia como la tomasiana no son estrictamente equiparables a las teorías contemporáneas en las que la correspondencia se entiende, en la mayoría de los casos, al interior de un lenguaje previamente fijado y no por la relación con la realidad entendida como existente en sí misma. Además, en Tomás la doctrina de la correspondencia tiene un matiz especial pues depende de la realización, en aquello que es, del ser dado por el Creador. En este sentido, no se puede decir que lo verdadero "sea el caso" como en las teorías contemporáneas, sino más bien que lo verdadero imita a Dios del cual participa en el ser. Cf. Milbank \& Pickstock, Truth in Aquinas (Routledge, London and New York, 2001), 9 y 15.

Cf. Aristóteles, Metafísica II, 1, 993b 20-30 donde se trata la verdad desde una perspectiva ontológica. Por otra parte en Metafísica IX, 10, 1051b 1-17, se alude propiamente a la verdad lógica. 
concepto principalmente lógico (gnoseológico), pero con un fundamento ontológico. No hay verdad sin ser, porque la adecuación se da entre el entendimiento y el ser de la cosa, pero el ser de la cosa tiene una función veritativa en la medida que se relaciona con un entendimiento, en este caso, con el entendimiento divino. La noción de medida vuelve a aparecer, no ya desde la cosa con respecto al entendimiento, sino que ahora desde el entendimiento divino con respecto a la $\operatorname{cosa}^{47}$. Esta se ajusta, se adecúa, al entendimiento que la conoce en su ser, porque le otorga el ser: "Así, pues, el entendimiento divino mide y no es medido; la cosa natural en cambio, mide y es medida, pero nuestro entendimiento es medido: no mide ciertamente las cosas naturales sino solo las artificiales” ${ }^{38}$.

\subsection{La analogía de la verdad}

La noción de verdad que maneja Tomás de Aquino es esencialmente análoga. Él mismo establece una analogía de atribución en la que la verdad está primero y propiamente en el entendimiento divino, propia y secundariamente en el entendimiento humano e impropia y secundariamente en las cosas. Respecto a esta última forma de realizarse la verdad, puntualiza que se da la verdad en las cosas solo en cuanto referida a una de las otras dos verdades. Es decir, la relación con un entendimiento permanece en todos los analogados como la razón de la cual todos ellos participan $^{49}$.

Tal como dice en el artículo cuatro, esta analogía está, de alguna manera, anticipada en el artículo dos, en el que explica de qué manera se aplica la noción de medida en los diversos casos o formas de verdad.

47 Encontramos un enfoque que destaca la teoría de la participación en J. Milbank and C. Pickstock, Truth in Aquinas, 3: "For it will be shown that Aquinas's fundamental theory of truth is as theological as it is philosophical, and is only a correspondence theory in a sense which depends entirely upon the metaphysical notion of participation in the divine Being. [...] more generally he supposes that any truth whatsoever is a participation in the eternally uttered Logos".

De veritate, I, 2: sic ergo intellectus divinus est mensurans non mensuratus et non mensurans, res autem naturalis mensurans et mensurata, sed intellectus noster mensuratus et non mensurans res quidem naturales, sed artificiales tantum.

49 Cf. De veritate, I, 4. En pocas ocasiones Tomás de Aquino parece centrar la atención en la verdad de la cosa, por ejemplo cuando afirma que "la realidad de las cosas es, por decirlo así, su luz" (In de Causis, 1, 6). En este caso alude a que la razón de la inteligibilidad de las cosas está en su ser, el que, de alguna manera, expresa su verdad. 
La primera diferencia se establece entre el entendimiento práctico y el especulativo: en el primer caso, el entendimiento es la medida de lo que hace; en el segundo, las cosas lo miden. Pero hay que añadir otra relación de medida que es la que realiza el entendimiento divino que mide todas las cosas naturales por ser su creador. El esquema final es que el entendimiento humano es medido - por las cosas- y mide aquellas que fabrica. La cosa natural mide y es medida. Dios, finalmente, mide, pero no es medido ${ }^{50}$.

Podemos ahora plantear qué sucede en el caso de Dios con la noción de adecuación que es la que define la verdad. ¿Hay alguna forma de adecuación en el entendimiento divino y cómo podría darse si Él es la causa de todo lo creado? ¿Puede darse en Él una relación como se da en la adecuación? Tomás responde a esta cuestión en el artículo siete comenzando por una distinción entre la verdad en Dios en sentido propio y metafórico. En sentido propio, la verdad en Dios es una igualdad entre su entendimiento y su esencia divina. De esta verdad se sigue la igualdad entre el entendimiento divino y las cosas creadas, porque estas son conocidas en su esencia. En sentido metafórico, se puede hablar de la verdad divina como principio. Este no es un uso propio porque solo se aplica a la igualdad que se realiza en Dios como principio del Hijo. Las cosas creadas son verdaderas en cuanto imitan a Dios como principio, pero no realiza entre ellas y el principio la razón de igualdad ${ }^{51}$.

Atendiendo al sentido propio, que es el que ahora interesa, volvamos sobre la noción de igualdad que menciona el Aquinate, para precisar que en ella no se da la noción de medida que caracteriza la adecuación entre el entendimiento la cosa: "el entendimiento divino y su esencia no se adecúan recíprocamente como la medida a lo medido" 52 . En Dios se realiza la noción de verdad, la adecuación, pero de una manera perfecta, es decir, como igualdad. Dios es su esencia y por esta razón la relación al entendimiento que está en toda forma de verdad, se da en Él como igualdad. Es un entendimiento que mide, pero no es medido, pero del cual se puede predicar la verdad como igualdad entre la verdad de su ser y la verdad de su entendimiento que son una y la misma. La medida que

50 Cf. De veritate, I, 2, corpus.

51 Cf. De veritate, I, 7, corpus; S. Th., I, 39, 8, corpus.

52 De veritate, I, 7, corpus: Intellectus autem divinus et essentia divina non adaequantur ad invicem sicut mensurans et mensuratum. 
realiza el entendimiento divino con respecto a las cosas creadas, proviene de esta primera y perfecta verdad, porque en su esencia están contenidas las verdades de todas las cosas. La pregunta que surge es si se da en este caso propiamente la adecuación, razón formal de la verdad, porque antes ha dicho Tomás que lo mismo no se adecúa a sí mismo, sino que es una igualdad de cosas diversas ${ }^{53}$.

Wippel resuelve el problema afirmando que sin duda Tomás de Aquino considera que Dios es la verdad, la verdad primera y suprema. Pero también es claro que Tomás reemplaza en el caso de Dios la noción de adecuación por la de igualdad, porque hay una identidad entre el entendimiento divino y su esencia ${ }^{54}$.

Tendríamos que concluir que la analogía de la verdad solo se verifica en Dios en la medida que es el entendimiento que más propiamente mide aquello que conoce en su calidad de creador. Bajo esa razón o respecto, lo creado se adecua a su entendimiento, porque es distinto de Dios. Pero si consideramos que Dios es aquello que es más propiamente verdadero en sí mismo, tenemos que decir que es también aquello que es más perfectamente idéntico a sí mismo. Por esta razón, la verdad en Dios se realiza más plenamente por su carácter ontológico y no por el lógico, por la perfección de su ser y no por la perfección de una adecuación entre el cognoscente y lo conocido.

\subsection{El juicio como lugar de la verdad}

La definición de la verdad como adecuación tiene otra consecuencia: la verdad se da propiamente en el juicio y de un modo impropio en la simple aprehensión. La razón es que la verdad se realiza en el decir o enunciar algo acerca de algo que se corresponda con lo que este algo es. En la simple aprehensión no hay verdad, en sentido propio porque no hay un decir acerca de algo, sino la simple captación de ese algo. Esta captación puede ser verdadera, la mayor parte de las veces lo es, pero no tiene por finalidad expresar una verdad, como sí lo hace el juicio. Tomás lo explica diciendo que "lo mismo no se adecúa a sí mismo, sino que es

53 Cf. De veritate, I, 3, corpus.

54 Cf. J. F. Wippel, «Truth in Thomas Aquinas», en Review of Metaphysics, 43 (December 1989), 295-326, 299. "Truth in Thomas Aquinas II", en Review of Metaphysics, 43 (March 1990), 543-567, 546-549. 
igualdad de cosas diversas" 55 . Esta diversidad no se da en la simple aprehensión en la que el entendimiento se hace uno con aquello que conoce. En cambio, al juzgar, el entendimiento tiene algo propio que no está en la cosa, sino exclusivamente en la mente, pero que debe ajustarse a la $\operatorname{cosa}^{56}$. Eso propio es el decir o enunciar sobre algo, de manera que hay dos realidades diversas entre sí: el decir del que conoce y el ser de la cosa. Entre estos dos términos diversos se da la adecuación. En la verdad del juicio hay, por así decir, una novedad pues el entendimiento advierte, al juzgar, un rasgo o una propiedad de la cosa y le otorga el estatuto de ser un rasgo o una propiedad conocida por él. En este sentido, la verdad procede principalmente del juicio ${ }^{57}$.

\subsection{El carácter reflexivo de la verdad}

Tomás de Aquino añade a la doctrina aristotélica el carácter reflexivo de la verdad. Si la verdad está en el entendimiento, este debe conocer su ser verdadero:

[La verdad] es conocida por el entendimiento en cuanto que este retorna sobre su propio acto; no solo en cuanto conoce su propio acto, sino en cuanto que conoce su adecuación a la cosa, la cual solo puede conocerse si conoce la naturaleza de su acto. [...] En consecuencia, el entendimiento conoce la verdad en cuanto retorna sobre sí mismo ${ }^{58}$.

55 De veritate, I, 3, corpus: idem autem non adaequatur sibi ipsi sed aequalitas diversorum est.

56 De veritate, I, 3: ubi primo intellectus incipit aliquid proprium habere quod res extra animam non habet. En cambio esto propio no se da en la simple aprehensión: quod quamvis formatio quidditatis sit prima operatio intellectus, tamen per eam non habet intellectus aliquid proprium quod possit rei adaequari et ideo non est ibi proprie veritas: Ibid. ad 1. En el Comentario al Peri hermeneias Tomás DE AQUINo se refiere a la doble acepción de la verdad y al lugar propio de la verdad lógica en el juicio: Ad huiusmodi igitur evidentiam considerandum est quod veritas in aliquo invenitur dupliciter: uno modo, sicut in eo quod est verum: alio modo, sicut in dicente vel cognoscente verum. Invenitur autem veritas sicut in eo quod est verum tam in simplicibus, quam in compositis; sed sicut in dicente vel cognoscente verum, non invenitur nisi secundum compositionem et divisionem (Libro I, Lectio 3, n. 6).

57 Cf. A. Llano, quien hace ver la paradoja de que lo verdadero se da gracias a la no identidad entre el conocimiento o el juicio y la cosa. En este sentido el ser verdadero no es el mismo ser de la cosa, aunque se fundamente en este. Cf. "“Being as True" according to Aquinas», 79 y 81 .

58 De veritate, I, 9: cognoscitur autem ab intellectu secundum quod intellectus reflectitur super actum suum, non solum secundum quod cognoscit actum suum sed secundum 
Algunos comentaristas añaden que se trata de un conocimiento concomitante al de la cosa conocida, no de un acto cognoscitivo posterior ${ }^{59}$. Es importante mencionar esta característica de la verdad porque refuerza la posesión de la verdad por parte del entendimiento y reafirma la idea de que la verdad es propiedad propia y principalmente de la mente ${ }^{60}$.

\section{Puntos de contacto y divergencias entre las Visiones de Ansel- MO Y TOMÁS SOBRE LA VERDAD}

\subsection{Dios es la verdad}

Aunque hay coincidencia entre ambos autores en la primacía de la summa veritas respecto de la verdad que se realiza en los entes particulares, esta preeminencia es interpretada de manera diferente en cada uno de ellos. La afirmación de que Dios es la verdad en grado sumo es una exigencia propia de todo pensador cristiano, porque los textos bíblicos indican que "Dios es la verdad" ${ }^{1}$. En un sistema teológico-filosófico cristiano debe argumentarse racionalmente cómo debe entenderse este postulado y cómo se vincula con nuestra experiencia cotidiana de la verdad.

La respuesta anselmiana debe entenderse como una subordinación de las verdades particulares a la Verdad divina a través del concepto de rectitudo: todo lo que es verdad, lo es porque cumple su fin determinado por Dios, en quien la rectitud es idéntica a sí mismo. Se puede decir que la verdad que realizan los seres es una participación de esta verdad única y suprema, por esta razón se da en ellos una rectitud limitada. Solo la summa veritas, causa de toda verdad es rectitud en un sentido propio, a saber, rectitud como identidad. La vinculación de la verdad con el fin propio de los seres es una nota característica del concepto de verdad que utiliza Anselmo. Desde esta perspectiva, Dios se concibe como la summa

quod cognoscit proportionem eius ad rem, quae quidem cognosci non potest nisi cognita natura ipsius actus. [...] unde secundum hoc cognoscit veritatem intellectus quod supra se ipsum reflectitur. Ver texto paralelo en STh.I, 16, 2.

59 Cf. A. Millán-Puelles, La estructura de la subjetividad (Rialp, Madrid, 1967); C. Segura, La dimensión reflexiva de la verdad: una interpretación de Tomás de Aquino, (Eunsa, Pamplona, 1991).

60 Cf. J. F. WippeL, «Truth in Thomas Aquinas II», 562.

${ }^{61}$ Cf. Jn 14, 6. 
veritas tanto porque en Él se realiza plenamente la rectitud, como también porque es el fin al cual tiende todo lo creado.

En el caso de Tomás, la concepción de Dios como summa veritas es abordado desde diferentes perspectivas tanto en su De Veritate como en la Suma Teológica, coincidiendo en ambos textos en la afirmación teológica de que Dios es la Verdad de la que deriva toda verdad creada. En el De veritate predomina la concepción analógica de la verdad por la que se afirma que el lugar propio y principal de la verdad es el entendimiento divino, mientras que en el entendimiento humano y en las cosas la verdad se da de modo análogo, tal como se señaló en el número anterior ${ }^{62}$. En la Suma Teológica se acentúa la identidad entre el ser divino y su verdad. En Dios no se da la adecuación propia de los seres creados, porque su ser no se conforma a su entendimiento, sino que es su mismo entendimiento. De aquí se desprende una relación de medida del entendimiento divino respecto a cualquier otro ser y entendimiento ${ }^{63}$. Tanto la noción analógica de verdad, como la de medida, dan cuenta de la subordinación de las verdades particulares a la summa veritas como lo causado se subordina a su causa. Pero, a la vez, permiten atribuir a los seres particulares una verdad propia e intrínseca, porque cada cosa es verdadera por su ser, que opera como su propia medida, y el entendimiento es verdadero al adecuarse al ser de la cosa conocida, es decir, al ser medido por ella.

\subsection{El lugar de la verdad: cosa y entendimiento}

Entre ambos autores encontramos una diferencia relevante al detectar cuál es el lugar de la verdad, es decir, en qué sujeto se realiza formalmente lo verdadero, o en términos contemporáneos, cuál es el truthbearer. En el caso de Anselmo de Canterbury, se reconocen distintas sedes veritatis, en las que la verdad se realiza a su modo, en cuanto un sujeto determinado hace lo que debe hacer. De esta forma, la verdad de la proposición o de la acción se entiende como el cumplimiento de un cierto deber recibido. El lugar de la verdad es aquello mismo que se entiende como verdadero. Ahora bien, la definición alcanzada por Anselmo destaca un aspecto cognoscitivo al llamarla rectitudo sola mente perceptibilis ${ }^{64}$.

62 Cf. De veritate, I, 4.

63 Cf. STh, I, 16, 5.

64 Este aspecto es ampliamente explorado por G. LöHrer «Ontologisch oder epistemisch? Anselm von Canterbury über die Begriffe Wahrheit und Richtigkeit» en Recherches de Théologie et Philosophie Médiévales 2/69 (2002), 296-317. 
Es decir, una propiedad del hecho de que algo sea verdadero es que, al mismo tiempo, tiene que ser necesariamente perceptible por la mente. Este aspecto, no obstante, no significa que el lugar de la verdad sea el intelecto propiamente tal, puesto que lo que la definición designa es que lo verdadero es apto de ser percibido por la mente, y no necesariamente percibido en acto $^{65}$. Por tanto, el lugar propio de la verdad es la cosa puesto que es el sujeto que realiza formalmente lo verdadero.

En el pensamiento de Tomás de Aquino, la realización de la verdad no se da formalmente en la cosa, sino en la conformidad actual, no meramente posible, con el intelecto. Así, lo verdadero es lo ya adecuado y no lo meramente adecuable. No es una propiedad intrínseca de la cosa lo que la constituye como verdadera, sino el hecho de que ella se conforme a un intelecto. Ahora bien, en cuanto todas las cosas se conforman al intelecto divino que las mide, todo lo existente y lo posible, realiza formalmente lo verdadero. Propiamente tal, afirma Tomás, hay verdad en el juicio verdadero, es decir en la afirmación o negación de un cierto estado de $\operatorname{cosas}^{66}$. Los demás órdenes de verdad, como por ejemplo el sentido, reciben el predicado de verdadero de forma impropia. Para Anselmo, por el contrario, no hay una diferencia fundamental entre los distintos sujetos de la verdad, aunque reconoce que utilizamos con mayor frecuencia el término verdadero en el juicio o enunciado ${ }^{67}$. Por lo demás, en el mismo diálogo De Veritate el Cantuarense muestra una preferencia por analizar problemas particulares siguiendo el modelo de la rectitud de la enunciación ${ }^{68}$. La verdad del enunciado no es más propia que la de la acción, sin embargo, Anselmo reconoce en ella con mayor claridad la estructura fundamental de la rectitudo.

\subsection{Diferencia entre rectitudo y adaequatio}

Por último, cabe hacer una consideración conceptual en relación a los términos que cada autor considera como género próximo de la verdad. La rectitudo anselmiana parece ser distinta de la adaequatio tomasiana.

65 Agradecemos al profesor Santiago Orrego Sánchez habernos llamado la atención sobre este punto.

66 Cf. supra 3.5.

${ }_{67}$ Cf. DV II, 177; supra nota 6.

68 Por ejemplo, DV IX, 188: [R] edeamus ad ueritatem significationis, a qua ideo incepi, ut te a notioribus ad ignotiora perducerem. Cf. también DV XIII, 197 y ss. 
Un breve análisis de la recepción de la definición de Anselmo y del concepto de rectitudo por parte de Tomás nos permitirá atisbar la diferencia. Hay tres momentos en los que el Aquinate discute explícitamente la definición anselmiana de la verdad y en cada uno de ellos presenta una posición distinta sobre ella.

$1^{\circ}$ En el Comentario a las Sentencias Tomás reconoce que distintos autores han planteado diversas definiciones de la verdad, destacando distintos aspectos del concepto ${ }^{69}$. Finalmente, tras exponer e interpretar una serie de definiciones, afirma que "algunos han dado la definición de verdad comprendiendo todas las acepciones de la verdad, esto es: la verdad es la rectitud perceptible solo por la mente". Sin mencionar su autor, Tomás cita textualmente la definición de Anselmo y explica sus partes: "en la rectitud se aborda la conmesuración" y en su especificación se aborda "lo que satisface el concepto de verdad" (id quod complet rationem veritatis). Esta definición sería la más completa de todas las ofrecidas $^{70}$.

$2^{\circ}$ En las Cuestiones Disputadas sobre la Verdad Tomás agrupa las definiciones en tres clases: las que definen la verdad en virtud de su causa; las que apuntan a la ratio misma de la verdad, incluyendo cosa e intelecto; y las que designan su efecto ${ }^{71}$. El segundo grupo contiene solo dos definiciones: adaequatio intellectus et rei y rectitudo sola mente perceptibilis, atribuyéndosela explícitamente a Anselmo. Ahora bien, a renglón seguido, Tomás pareciera reducir el género próximo de la segunda a la primera: "En efecto, esta rectitud se dice según una cierta adecuación"72. La rectitud de la que estamos hablando en el caso de la verdad, debe

69 I Sent $\mathrm{d} 19 \mathrm{q} 5 \mathrm{a} 1$ in c: Sic ergo patet quomodo diversae definitiones de veritate dantur.

70 I Sent loc. cit.: Quaedam autem datur de veritate, comprehendens omnes veritatis acceptiones, scilicet: veritas est rectitudo sola mente perceptibilis. In rectitudine tangitur commensuratio; et in hoc quod dicitur sola mente perceptibilis, tangitur id quod complet rationem veritatis

71 De Veritate I, 1: Uno modo secundum illud quod praecedit rationem veritatis, et in quo verum fundatur (...) Alio modo definitur secundum id in quo formaliter ratio veri perficitur (...) Tertio modo definitur verum, secundum effectum consequentem. Cf. También C. Kann, "Wahrheit als "Adaequatio". Bedeutung, Deutung und Klassifikation» en Recherches de Théologie et Philosophie Médiévales, 2/66, (1999), 209-224.

72 De Veritate I, 1: Alio modo definitur secundum id in quo formaliter ratio veri perficitur; et sic dicit Isaac quod veritas est adaequatio rei et intellectus; et Anselmus in Lib. de 
ser entendida bajo el concepto de adecuación. Esto indicaría una preferencia por la noción de adecuación por sobre rectitud como concepto técnico que expresa mejor la correspondencia que existe entre la cosa y el intelecto.

$3^{\circ}$ En la Suma Teológica indica que "la verdad se describe de diversos modos"73, específicamente dos: en el primero, están las definiciones que la expresan "en cuanto está en el intelecto", mientras que en el segundo, están las definiciones que explican "la verdad de la cosas según su ordenación al intelecto" ${ }^{\prime 4}$. En la segunda clase, junto una definición de Agustín y la de Avicena, aparece la definición de Anselmo, que comenta así: "la verdad es la rectitud perceptible solo por la mente, porque es recto lo que concuerda con un principio". Todas estas definiciones, no obstante, se subordinan a la de adaequatio que sería la única que incluye ambas dimensiones: expresa el hecho de que la verdad está en el intelecto y de que está en ordenación hacia él ${ }^{75}$.

Se ve que la recepción que hace el Aquinate de la definición anselmiana no es homogénea, pues en cada momento hay una evaluación distinta sobre la pertinencia total o parcial de esta definición. Cabe preguntarse ¿qué aspectos del sentido anselmiano de este término son los que no le parecen apropiados para expresar convenientemente el concepto de verdad? La hipótesis que queremos plantear es que al parecer Tomás nota que el concepto de rectitud, si bien designa el componente relacional propio de la verdad, tiene una connotación teleológico-normativa que, en estricto rigor, no cabría atribuir a la ratio veritatis.

Esto ya parece ser advertido por el Aquinate en la citada distinción 19 del Comentario a las Sentencias, donde se objeta sobre la utilización del

veritate: veritas est rectitudo sola mente perceptibilis. Rectitudo enim ista secundum adaequationem quamdam dicitur (...). (El subrayado es el del original).

73 STh. I, 16, 1: (...) veritas diversimode notificatur.

74 Ibid. Et hoc pertinet ad veritatem secundum quod est in intellectu. Ad veritatem autem rei secundum ordinem ad intellectum, pertinet definitio Augustini in libro de vera Relig., veritas est summa similitudo principii, quae sine ulla dissimilitudine est. Et quaedam definitio Anselmi, veritas est rectitudo sola mente perceptibilis; nam rectum est, quod principio concordat. Et quaedam definitio Avicennae, veritas uniuscuiusque rei est proprietas sui esse quod stabilitum est ei. (El subrayado es el del original).

75 Ibid.:Quod autem dicitur quod veritas est adaequatio rei et intellectus potest ad utrumque pertinere. 
concepto de rectitud, pues es claro que Anselmo "habla metafóricamente de la rectitud, ya que la rectitud estrictamente hablando es una propiedad del continuo" 76 . La rectitud es, propiamente tal (per se), una propiedad geométrica ${ }^{77}$. Esta comprensión metafórica de la rectitud, continúa la objeción, no puede ser algo propio de la verdad como rectitud del intelecto, ya que también se aplica a la bondad o la justicia. Tal como el mismo Anselmo indica ${ }^{78}$, ellas también son rectitudes perceptibles solo por la mente, en las cuales también se utiliza el término 'rectitud' en forma metafórica. Esto lleva a Tomás a explicitar la esencia del concepto de rectitudo: "En lo recto se encuentra efectivamente una cierta proporción igual de principio, medio y fin"79. Debe destacarse que esta descripción se aplica tanto para lo recto en el sentido geométrico como en el sentido intelectual o moral. Por ende, la rectitud tiene que ver con una cierta conformidad, lo que convierte a este término en apropiado para referirse tanto a la justicia, como a la bondad y la verdad. En este último caso, se le llama "rectitud de la verdad, según lo que no se aparta del orden de la conmensuración de la cosa y el intelecto" ${ }^{\prime 0}$. Esto muestra que, para Tomás, el concepto de rectitudo no queda restringido al ámbito cognitivo, sino que es más amplio, y ha de ser especificado (rectitudo veritatis).

Esta anotaciones permiten suponer que Tomás recoge la definición de Anselmo por el hecho de que indica una proporción o relación de conformidad, característica fundamental para su comprensión de la verdad. Sin embargo, al parecer toma conciencia progresivamente de las connotaciones involucradas en el concepto rectitudo. La teleología $-y$ por tanto la normatividad- está intrínsecamente vinculada a la noción de rectitud. Como vimos más arriba, para Anselmo la introducción del

76 I Sent $\mathrm{d} 19 \mathrm{q} 5 \mathrm{a} 1 \mathrm{arg}$ 4: Anselmus dicit, quod veritas est rectitudo sola mente perceptibilis. Constat autem quod loquitur metaphorice de rectitudine, quia rectitudo proprie dicta est passio continui.

77 Tomás de Aquino, Sententia libri Metaphysicorum V, lectio 13, n.14: Rectitudo enim est per se passio lineae, levitas autem superficiei, linea vero naturaliter est prior superficie.

78 Cf. DV Cap. XII.

79 I Sent $\mathrm{d} 19 \mathrm{q} 5 \mathrm{a} 1$. ad 4: (...) dicendum, quod rectitudo dicitur de bonitate, justitia et veritate, metaphorice, secundum diversas rationes. Invenitur enim in recto quaedam aequalis proportio principii, medii et finis.

80 I Sent d19 q5 a1. ad 4: (...) secundum autem quod non egreditur ordinem commensurationis rei et intellectus, dicitur rectitudo veritatis. 
concepto de rectitudo no se entiende como la sola conformidad o conmensuración de dos elementos, sino que aquello que se conforma tiene por referencia aquello a lo que debe conformarse y, al hacerlo, está realizando aquello para lo cual fue hecho. Por otra parte, la aproximación conceptual tomasiana de la verdad no se centra en las implicaciones normativas y teleológicas, propias del ámbito del bien ${ }^{81}$. Este aspecto no sería decisivo a la hora de definir y describir la ratio veritatis. Si la verdad en Anselmo tiene una connotación normativa, la de Tomás tiene una connotación descriptiva ${ }^{82}$. Este aspecto sería, entonces, la razón por la que Tomás toma distancia de la definición de Anselmo, optando por el concepto de la adaequatio, que no traería consigo connotaciones teleológicas como sucede con el concepto de rectitudo.

81 Cf. STh, I, 5, 4 donde Tomás vincula intrínsecamente la noción de bien y la de fin.

82 Como ya anotamos, se discute si es que adaequatio y correspondencia, en el sentido preciso que es utilizado en teorías contemporáneas sobre la verdad, son conceptos idénticos. Cf. KanN, "Wahrheit als "Adaequatio". Bedeutung, Deutung und Klassifikation». 
Resumen: Dos de los hitos más importantes sobre el tema de la verdad en el medioevo son el diálogo De Veritate de Anselmo de Canterbury y la Cuestión Disputada acerca de la verdad de Tomás de Aquino escritos con casi dos siglos de distancia. El artículo expone las ideas centrales de ambos textos y revisa la relación entre ambos. En su texto Tomás retoma la definición anselmiana de la verdad como "rectitud solo perceptible por la mente" sin asumirla completamente. Más bien ofrece una nueva comprensión de la verdad como "adecuación entre el entendimiento y la cosa”, en la que los elementos característicos de la rectitud anselmiana se diluyen.

Palabras clave: Anselmo de Canterbury, Tomás de Aquino, verdad, rectitud, adecuación o correspondencia.

Abstract: Two of the most relevant milestones on the subject of truth in the Middle Ages are the dialogue De Veritate of Anselm of Canterbury and the Disputed Question on Truth of Thomas Aquinas, written within two centuries. This article presents the core ideas of both of these milestones and explores the relationship between them. In his text, Aquinas reintroduces the Anselmian definition of truth as "rectitude only conceivable by the mind", without wholly taking it up. Rather, he offers a new understanding of truth as "adequacy between intellect and thing", in which the characteristic features of the Anselmian rectitude are diminished.

Keywords: Anselm of Canterbury, Thomas Aquinas, truth, rectitude, adequacy, correspondence. 
